\title{
Introducing the Atacama Desert
}

\author{
Alan T. Bull • Barbara A. Andrews • Cristina Dorador • Michael Goodfellow
}

Received: 6 April 2018/Accepted: 15 May 2018/Published online: 26 May 2018

(C) Springer International Publishing AG, part of Springer Nature 2018

\begin{abstract}
This brief introduction is intended to orientate the reader with respect to the principal environmental and historical features of the Atacama Desert, the oldest and continuously driest non-polar temperate desert on Earth. Exploration of its microbiology is relatively recent but both fundamental and applied research activities have grown dramatically in recent years reflecting the substantial interest in its microbial diversity, ecology, biogeochemistry, natural product potential and Mars-analogue properties of this unique and invigorating environment.
\end{abstract}

A. T. Bull $(\bowtie)$

School of Biosciences, University of Kent,

Canterbury CT4 6QD, UK

e-mail: A.T.Bull@kent.ac.uk

B. A. Andrews

Department of Chemical Engineering and Biotechnology, Centre for Biotechnology and Bioengineering (CeBiB),

University of Chile, Beauchef 851, Santiago, Chile

C. Dorador

Laboratory of Microbial Complexity and Functional Ecology, Institute of Antofagasta and Department of Biotechnology, Centre for Biotechnology and Bioengineering (CeBiB), Universidad de Antofagasta, Antofagasta, Chile

M. Goodfellow

School of Biology, Ridley Building, Newcastle

University, Newcastle upon Tyne NE1 7RU, UK
Keywords Extremobiosphere - Atacameños · Aymara $\cdot$ Microbiology $\cdot$ Conservation

\section{Location}

The Atacama Desert lies in the north of Chile and is located within the administrative divisions Region de Antofagasta to the north and Region de Atacama to the south. Extending for over $1000 \mathrm{~km}$ between latitudes $19^{\circ} \mathrm{S}$ and $30^{\circ} \mathrm{S}$ it is bounded by the Coastal Cordillera to the west and the Andean Cordillera to the east creating a major two-sided rain shadow that largely prevents moisture advection (Fig. 1). The Atacama Desert per se comprises plateau ranging in altitude from near sea level to about $3500 \mathrm{~m}$ above but the Atacama generally is taken to include the southern extent of the Altiplano, north-east of the Desert with an average elevation of about $3750 \mathrm{~m}$ above sea level ( $\mathrm{m}$ a.s.l.), and the bleak lower slopes of the Andes rising to over $5000 \mathrm{~m}$ a.s.1; the whole geography is overlooked by the chain of majestic Andean volcanoes. Features of each of these ecosystems are treated in this Special Issue.

What makes the Atacama biome of interest to microbiologists? Principally it is the recognition that it is the oldest and continuously driest non-polar temperate desert on Earth, believed to have been arid since the Jurassic period and gradually evolving to 


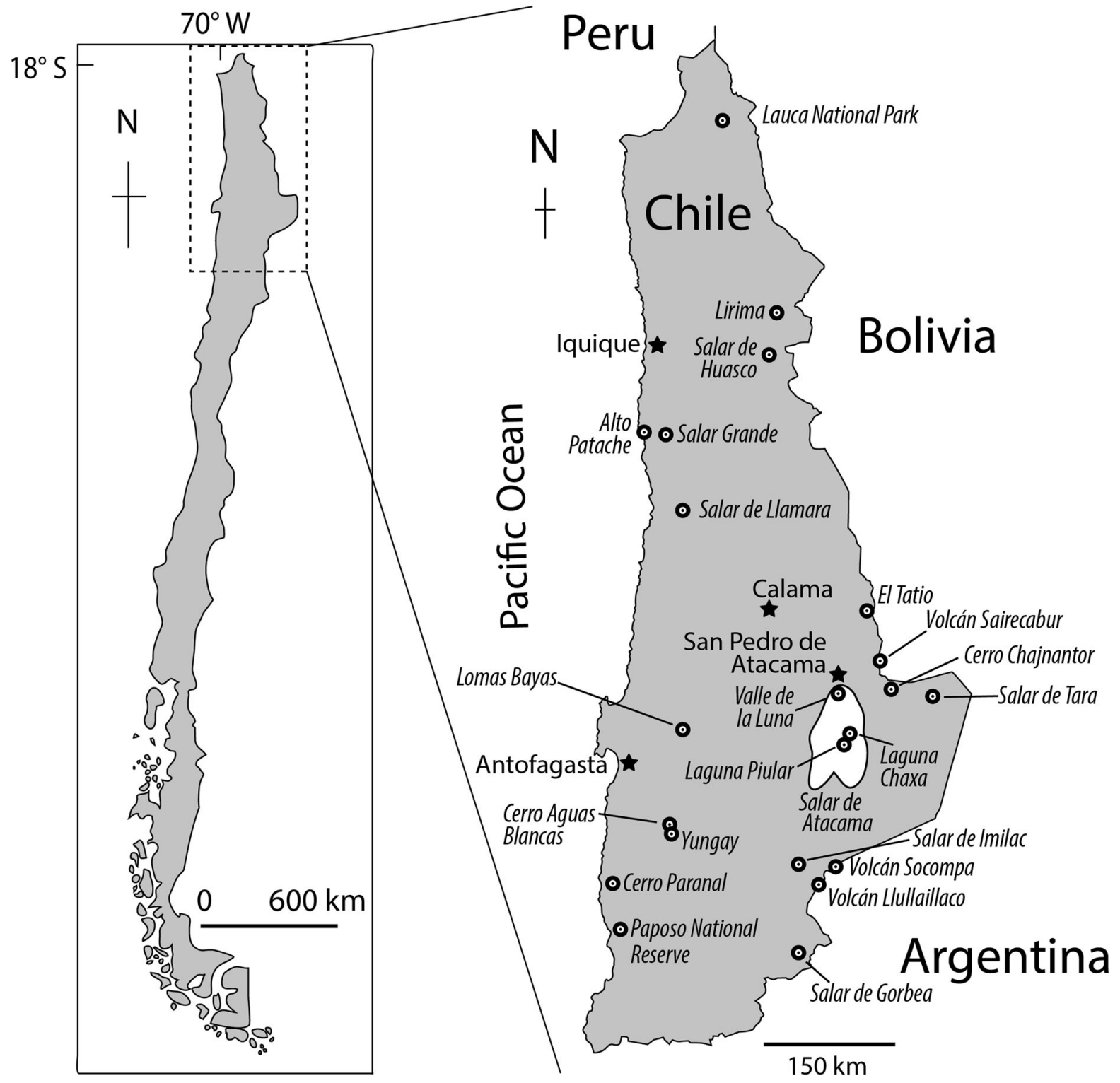

Fig. 1 Map of Northern Chile showing the locations of research sites referred to in papers of this Special Issue. Map drawn by Cristina Dorador and Dr Chris Harrod (Instituto de Ciencias Naturales Alexander von Humboldt, Universidad de Antofagasta)

hyper-aridity during the Miocene epoch over 5 million years ago. In addition exceptionally high UV radiation levels, extreme aridity, low or zero concentrations of soil carbon, and the presence of strong oxidizing conditions and/or toxic elements in particular habitats makes the Atacama a prime example of the extremobiosphere, the defining environmental limits to life on Earth (Bull 2011).

\section{Historical and cultural background}

The greater Atacama region is one of the least inhabited parts of Chile with populations centered in coastal and a few small tourism-orientated towns and village oases. Present-day indigenous peoples, the Atacameños, tend to be scattered in the Altiplano and be dependent on subsistent agriculture. Abandoned saltpetre mining communities are a feature of the desert zone itself. 
A Pre-Columbian culture of hunter-gatherers-the Licanantai-dates from about $12,000 \mathrm{Bp}$ and the Atacama Desert and Altiplano area in which it developed was named Atacama (Sp. atakama) by the Spanish conquistadores. Tulor (ca. $2500 \mathrm{Bp}$ ) and the Pucara de Quitor (ca. $700 \mathrm{Bp}$ ) are among the few extant remains of ancient adobe and of stone-built preInca settlements sustained by the San Pedro river that discharges into the Salar de Atacama. Today the Atacameños are one of the nine recognised indigenous peoples of Chile. Their art is captured in sand and rock geoglyphs dating from 1500 to 600 years $\mathrm{Bp}$ and is both symbolic and naturalistic in style. At the Altiplano there are also other indigenous people, the Aymaran, who are a dynamic and cultural rich population and mainly located in Peru and Bolivia.

The Atacama Desert remains a constant feature of the Chilean psyche as portrayed most vividly in the work of Chile's Nobel poet laureates Gabriela Mistral and Pablo Neruda, and by more recent poets such as Raul Zurita and Adrian Arancibia. Zurita is credited with creating the world's longest poem-literally over $3 \mathrm{~km}$ long - a geoglyph in the Atacama Desert that reads "ni pena, ni miedo," (without pain, without fear), a testimony to disappearances during the Pinochet regime. While Patricio Guzman's recent film masterpiece "Nostalgia for the Light' similarly reflects this latter grim human episode in Atacama Desert history, it also presents another face of this unique environment, namely its location of the world's largest astronomical observatory, ALMA (Atacama Large Millimeter/submillimeter Array). Given its extreme aridity, high altitude and protection from light pollution and radio interference the Chajnantor Plateau near the centre of the Desert was chosen by the European, North American and Japanese consortium as the ideal site for the multi-array observatory. Yet again history repeats itself as the origin of the word Chajnantor in the Licanantai kunza language means 'launch site' revealing that indigenous people had using been using the location to observe the skies possibly for millennia.

\section{A fragile environment}

The Atacama Desert holds rich reserves of several commercially valuable minerals. In the nineteenth century the world's largest deposit of sodium nitrate was extensively exploited for the production of fertilizers and explosives. Development of these massive deposits was a consequence of severe aridity thereby restricting their dissolution and denitrification. Copper production plays an important role in the current Chilean economy, the primary mining activities being located in the Norte Grande natural region with the world's largest open-cast copper mine "La Escondida" and Chuquicamata in the Atacama Desert per se. Adverse environmental impacts from these mining operations include a major requirement for water, and atmospheric, water and soil emissions of arsenic resulting from the processing of arsenic containing ores. Large scale water consumption also is required in salt extraction operations in parts of the Desert and lithium at the Salar de Atacama. Consequently, because water is an essential resource both for indigenous communities and mineral exploitation it has generated serious conflict in the Atacama (Babige 2016). Moisture depletion as a result of receding water tables (clearly evident at the former University of Antofagasta Yungay Research Station for example) also will have impacted on microbial colonisation of Atacama soils.

A final point to emphasise here relates to the growing recognition of the Atacama Desert as a huge reservoir of tractable and of 'dark' microbial matter, the substance of this Special Issue, an increasing knowledge of which is spurring bioprospecting for new microbial products including bioactive chemicals, biocatalysts, nutraceuticals and cosmetic materials. The growth of such activities brings into focus the significance of the Convention on Biological Diversity (CBD) both for national interests and those of the Atacameños and other indigenous populations. The three principal objectives of the CBD are: the conservation of biodiversity (inclusive of microbial diversity), the sustainable use of biodiversity, and crucially the fair and equitable sharing of benefits deriving from exploitation of genetic resources. It is in this context that we commented previously "It is of some concern that a substantial proportion of publications on Atacama Desert microbiology lack a Chilean coauthor or do not indicate that samples were collected with permission." (Bull et al. 2016). Therefore, we take this opportunity to present a special issue devoted to the Microbiology of the Atacama Desert that is international, interactive and inclusive in its scope. 


\section{Enter microbiology}

Only a decade and a half ago the core region of Atacama Desert was seen to represent "the dry limit of microbial life" (Navarro-Gonzalez et al. 2003) but we now know that this and other regions of the Desert are teeming with unexplored life, much of it microbial. We have discussed previously the very earliest findings of bacteria in Atacama soils and the weighty catalyst for further studies afforded by NASA's interest in this desert as a reasonable analogue for Martian soils (Bull and Asenjo 2013; Bull et al. 2016) and how Atacama microbiology was reenergised by Chilean scientists at the end of the last century. However, pursuit of the Atacama's microbiology has increased so dramatically during the early years of this century that we believed it was timely to take stock and provide a platform for future studies by devoting a special issue of Antonie van Leeuwenhoek to the microbiology and closely related sciences of the Atacama Desert.

This Special Issue opens with a selection of articles detailing the most salient physiochemical features of this hyper extreme environment, including the high altitude endorheic Altiplano northeast of the Atacama Desert, in order to provide a relevant and necessary backcloth for subsequent discussions of its microbiology. There follow papers on the microbial diversity and the range of ecosystems that are found in the Atacama, and the opportunities that genomic and metagenomic techniques are providing to reveal 'dark' microbial communities and adaptive mechanisms, and guide search and discovery campaigns.

Although microbiologists have made forays into other of the Earth's great deserts, the Atacama Desert in terms of its variety of ecosystems, its geology and geochemistry, its elevation, and its extremes of aridity and intensity of solar radiation distinguish it as unique and awe-inspiring biome for microbial exploration.

Conflict of interest The authors declare that they have no conflict of interest.

\section{References}

Babige S (2016) Contested value and an ethics of resources: water, mining and indigenous people in the Atacama Desert, Chile. Aust J Anthropol 27:84-103

Bull AT (2011) Actinobacteria of the extremobiosphere. In: Horikoshi K (ed) Extremophiles Handbook. Springer, Tokyo, pp 1203-1240

Bull AT, Asenjo JA (2013) Microbiology of hyper-arid environments: recent insights from the Atacama Desert, Chile. Antonie van Leeuwenhoek 103:1173-1179

Bull AT, Asenjo JA, Goodfellow M, Gomez-Silva B (2016) The Atacama Desert: technical resources and the growing importance of novel microbial diversity. Annu Rev Microbiol 70:215-234

Navarro-Gonzalez R, Rainey F, Molina P, Bagaley DR, Hollen BJ, de la Rosa J, Small AM, Quinn RC, Grunthaner FJ, Caceres L, Gomez-Silva B, McKay CP (2003) Mars-like soils in the Atacama Desert, Chile and the dry limit of microbial life. Science 302:1018-1021 